\title{
Correction to: Tussock microhabitats increase nitrogen uptake by plants in an alpine wetland
}

\author{
Yi-Heng Hu • Xiao-Ya Zhang $\cdot$ Kun Zhang • Ming-Hua Song • Jun-Qin Gao • \\ Maxim Dorodnikov · Andrey Soromotin · Yakov Kuzyakov
}

Published online: 19 October 2021

(C) Springer Nature Switzerland AG 2021

\section{Correction to: Plant Soil \\ https://doi.org/10.1007/s11104-021-05056-y}

The original version of this article, unfortunately contained an added text "plant biomass and root-to-shoot" after Author Xiao-Ya Zhang in author-group.

Publisher's note Springer Nature remains neutral with regard to jurisdictional claims in published maps and institutional affiliations.
The original article can be found online at https://doi.org/ 10.1007/s11104-021-05056-y

Y.-H. Hu · X.-Y. Zhang · J.-Q. Gao $(\bowtie)$

School of Ecology and Nature Conservation, Beijing

Forestry University, Beijing 100083, China

e-mail: gaojq@bjfu.edu.cn

\section{K. Zhang}

National Plateau Wetlands Research Center, Southwest

Forestry University, Kunming 650224, Yunnan, China

\section{M.-H. Song}

Key Laboratory of Ecosystem Network Observation and Modeling, Institute of Geographic Sciences and Natural Resources Research, Chinese Academy of Sciences, Beijing 100101, China
M. Dorodnikov · Y. Kuzyakov

Department of Soil Science of Temperate Ecosystems and Department of Agricultural Soil Science, University of Göttingen, 37077 Göttingen, Germany

M. Dorodnikov

Biogeochemistry of Agricultural Ecosystems, University of Göttingen, 37077 Göttingen, Germany

M. Dorodnikov · A. Soromotin · Y. Kuzyakov Tyumen State University, 625003 Tyumen, Russia

Y. Kuzyakov

Agro-Technological Institute, RUDN University, 117198 Moscow, Russia 